Supporting information;

\title{
A Comparative Langmuir-Blodgett Study on a Set of Covalently Linked Porphyrin-Based Amphiphiles: A Detailed Atomic Force Microscopic Study
}

Pei Sun ${ }^{\S}$, D. Amilan Jose, Atindra D. Shukla, Jignesh J. Shukla, Amitava Das ${ }^{*}$, James F. Rathman ${ }^{\star}$, and Pradyut Ghosh*.

Analytical Sciences, Central Salt \& Marine Chemicals Research Institute, Bhavnagar 364002, Gujarat, India; ${ }^{\S}$ Chemical and Biomolecular Engineering Department, The Ohio State University, Columbus, Ohio- 43210, USA.

\section{Content}

1. 4 pages NMR spectra $\left(\mathbf{L}_{\mathbf{1}}-\mathbf{L}_{\mathbf{4}}\right)$.

2. 4 pages Mass spectra $\left(\mathbf{L}_{1}-\mathbf{L}_{4}\right)$.

3. 1 page Electronic spectra for $\mathrm{L}_{4}$ in chloroform. 


\section{NMR spectra}

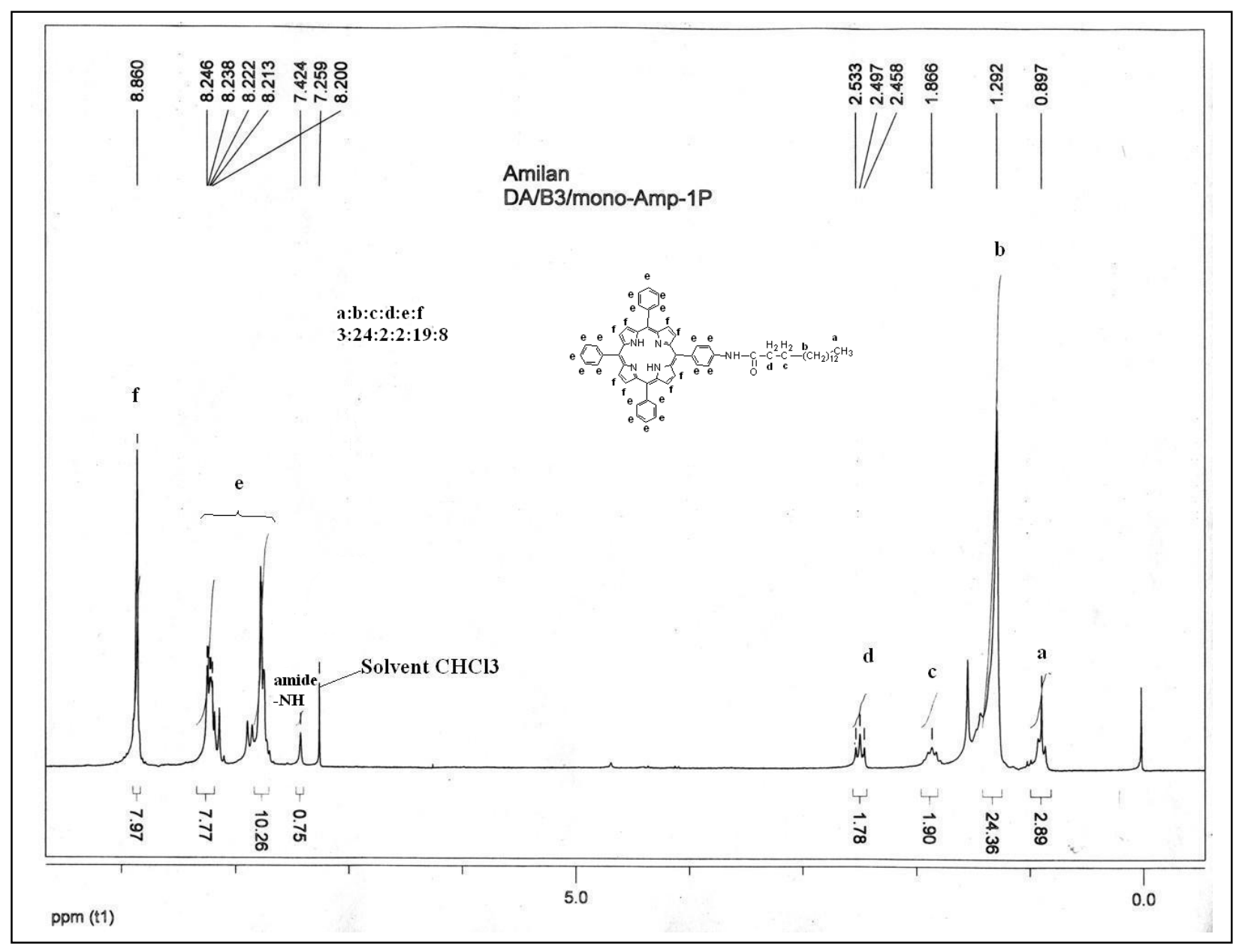




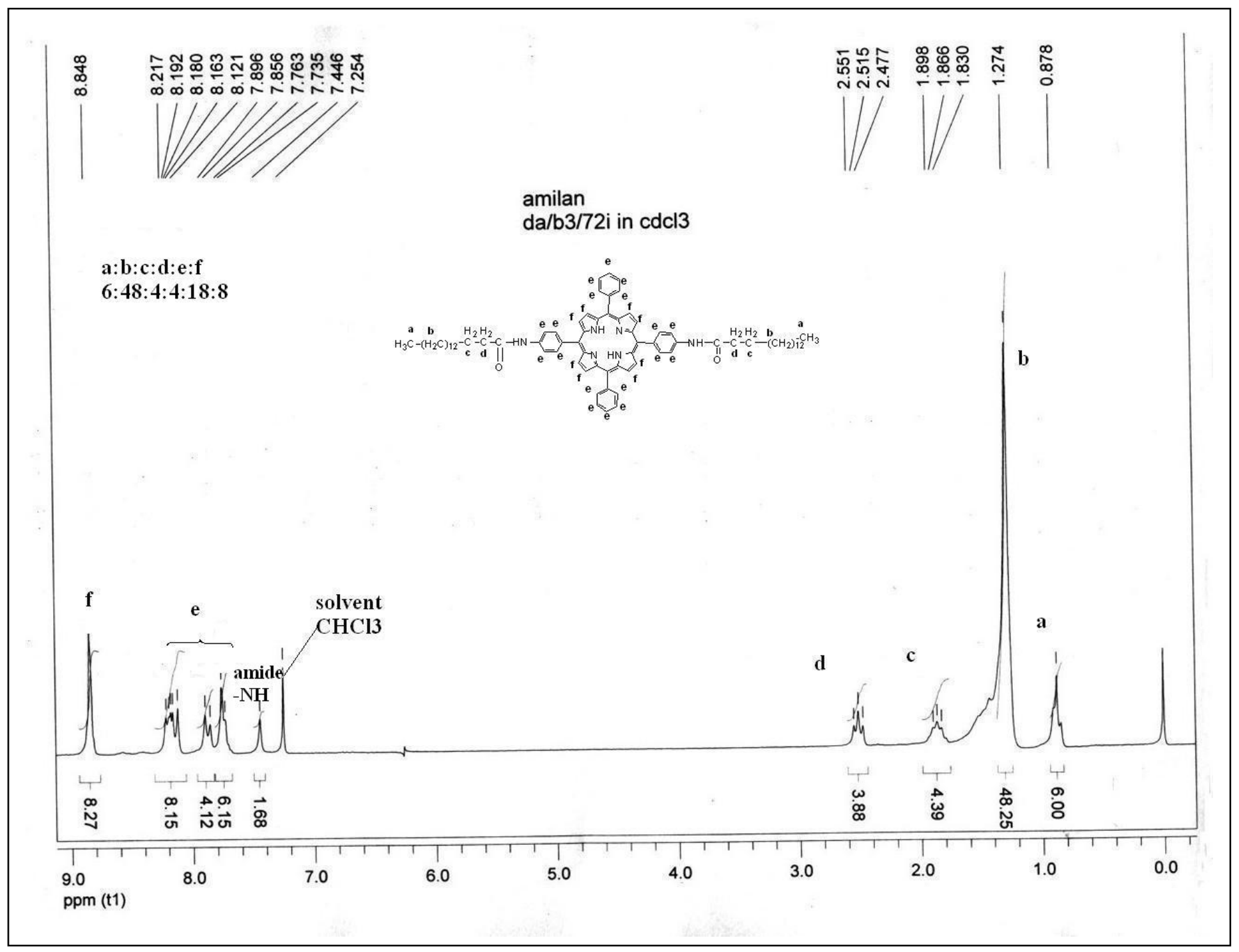




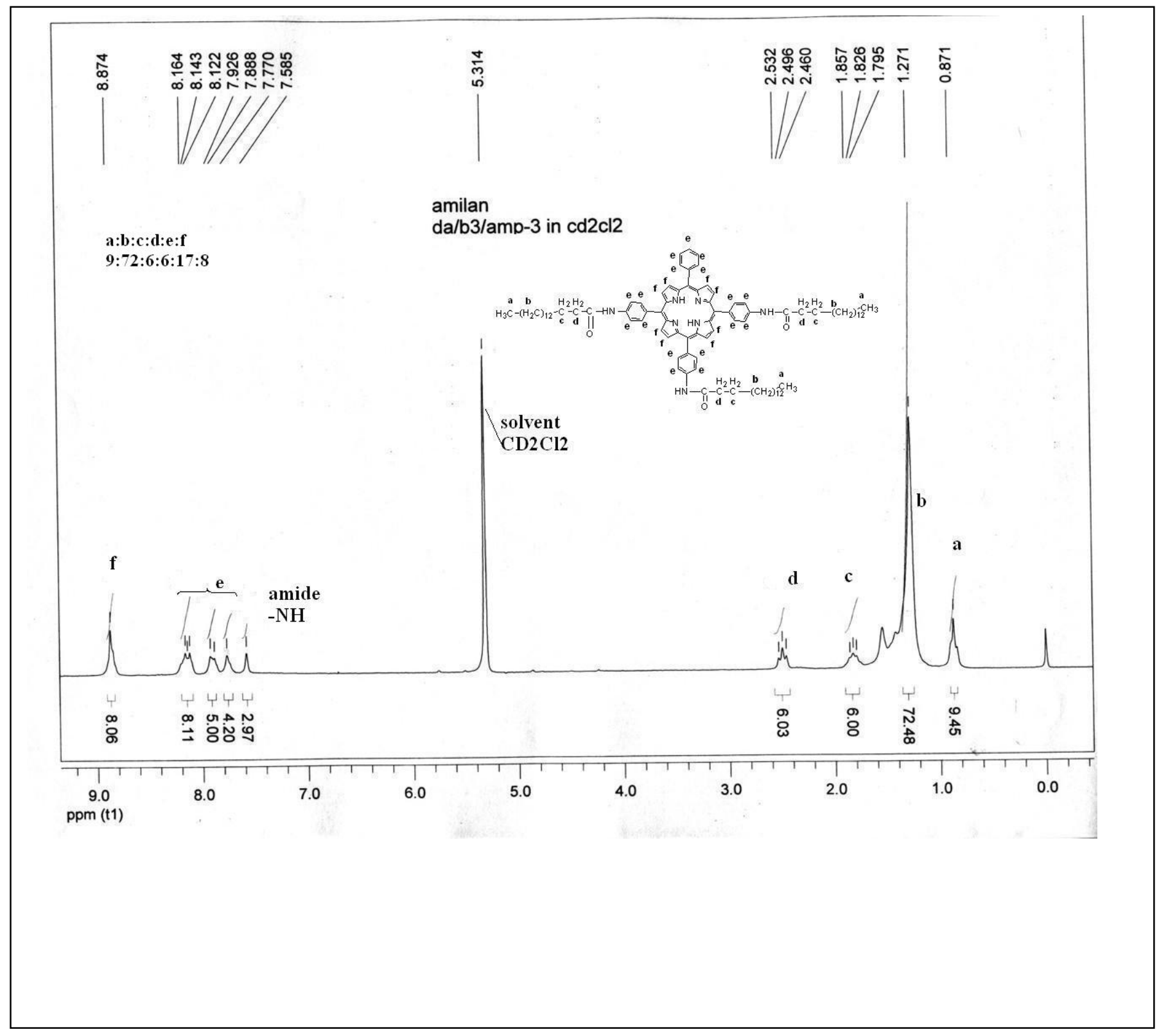




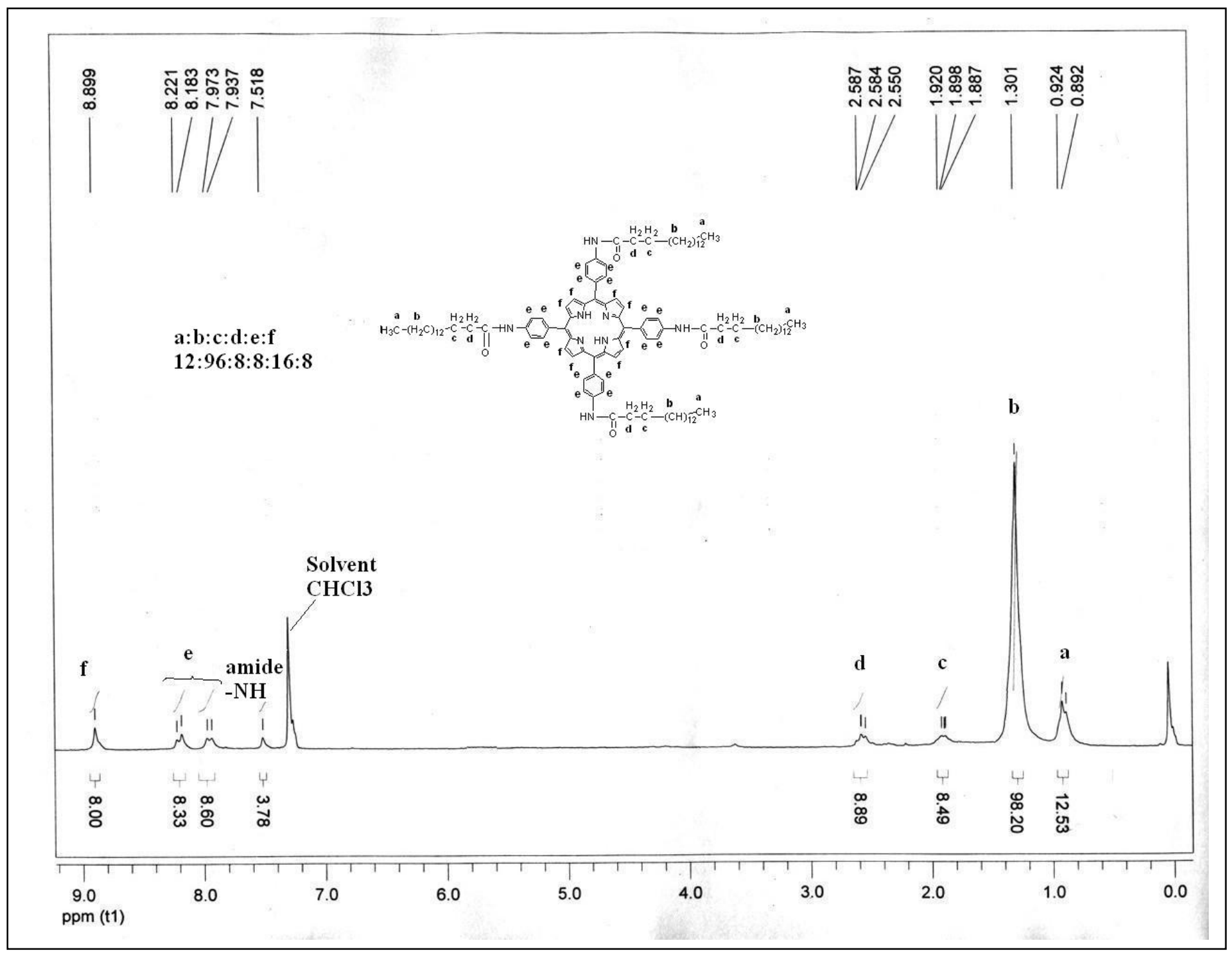




\section{Mass spectra}

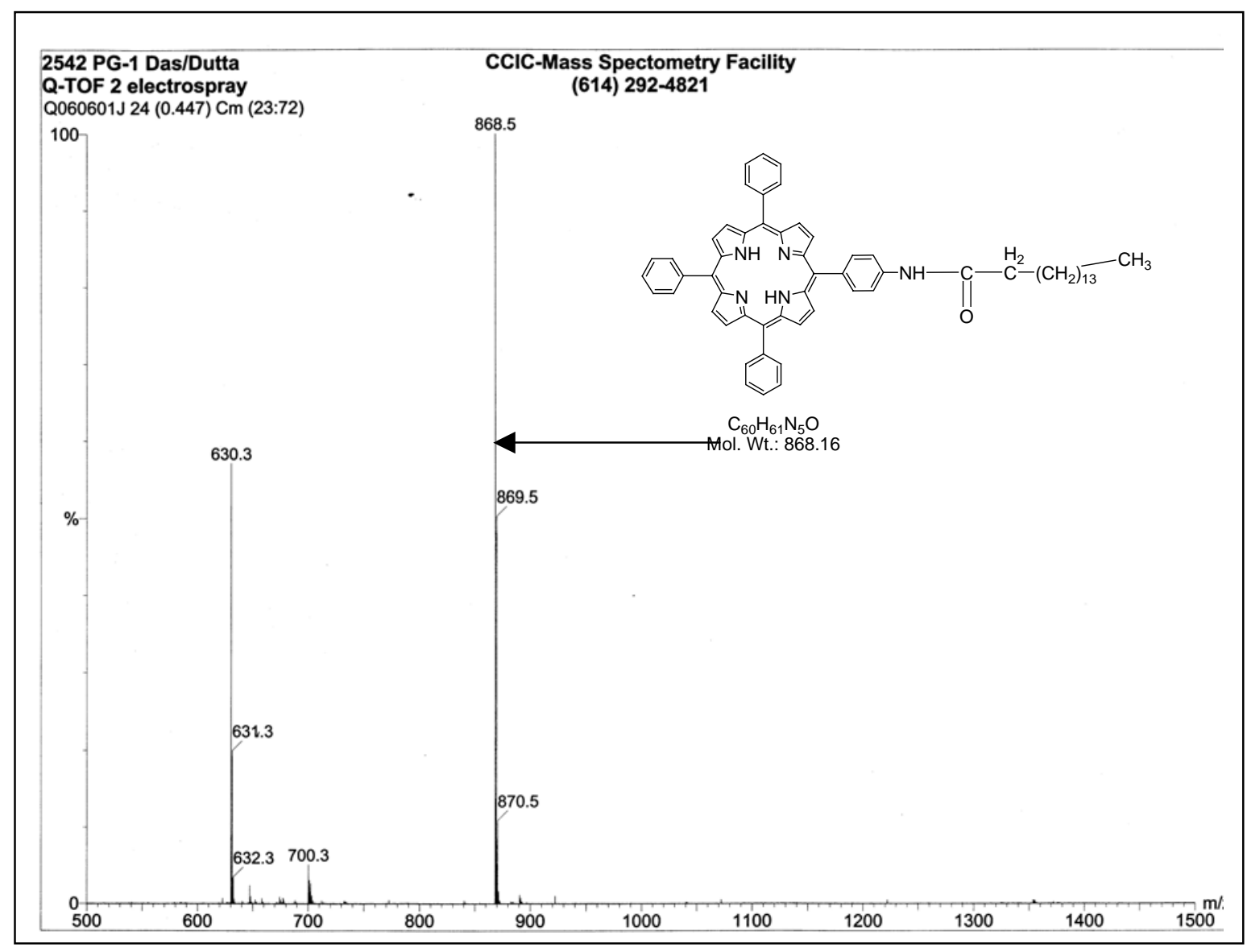




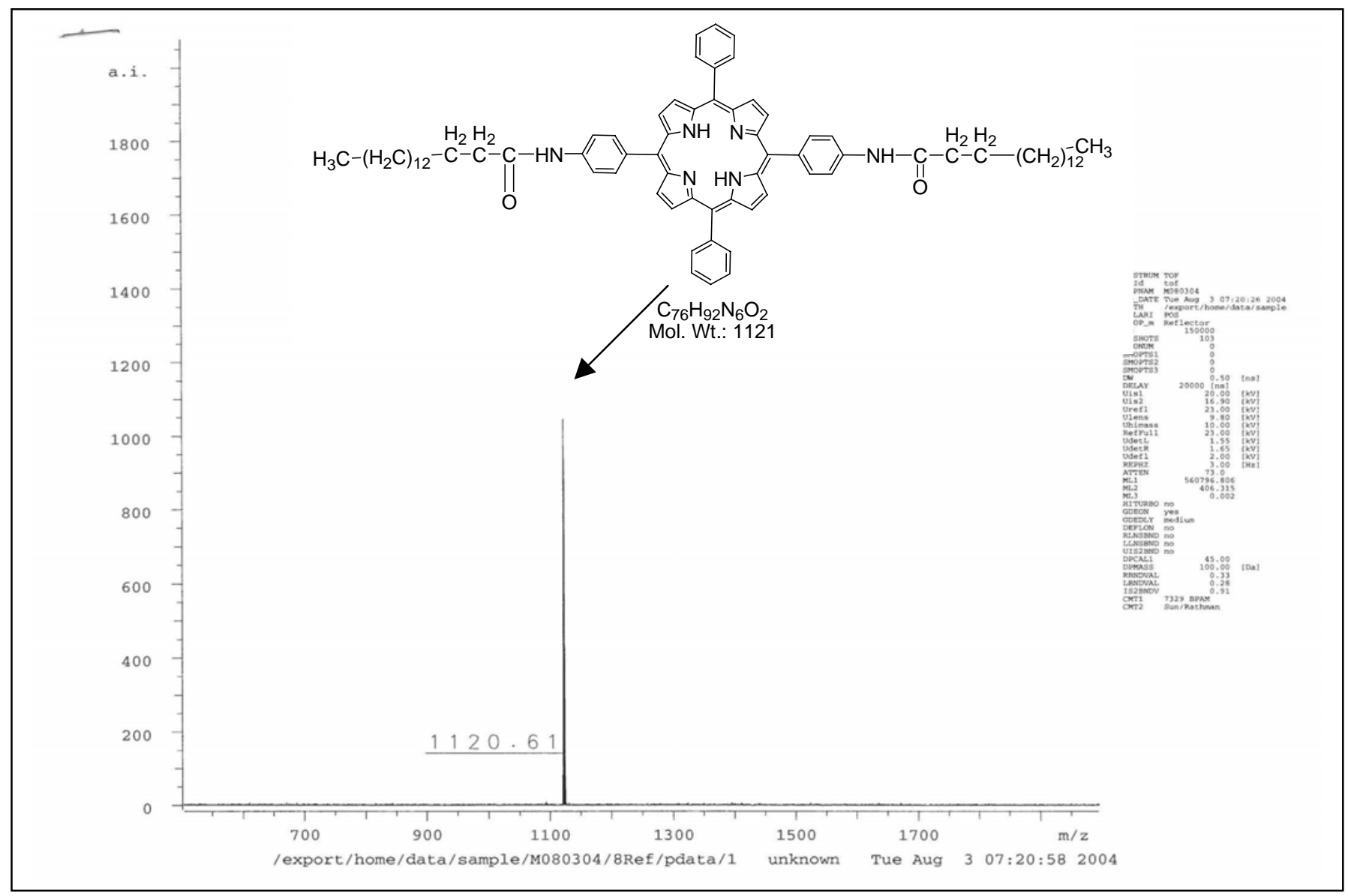

S6 


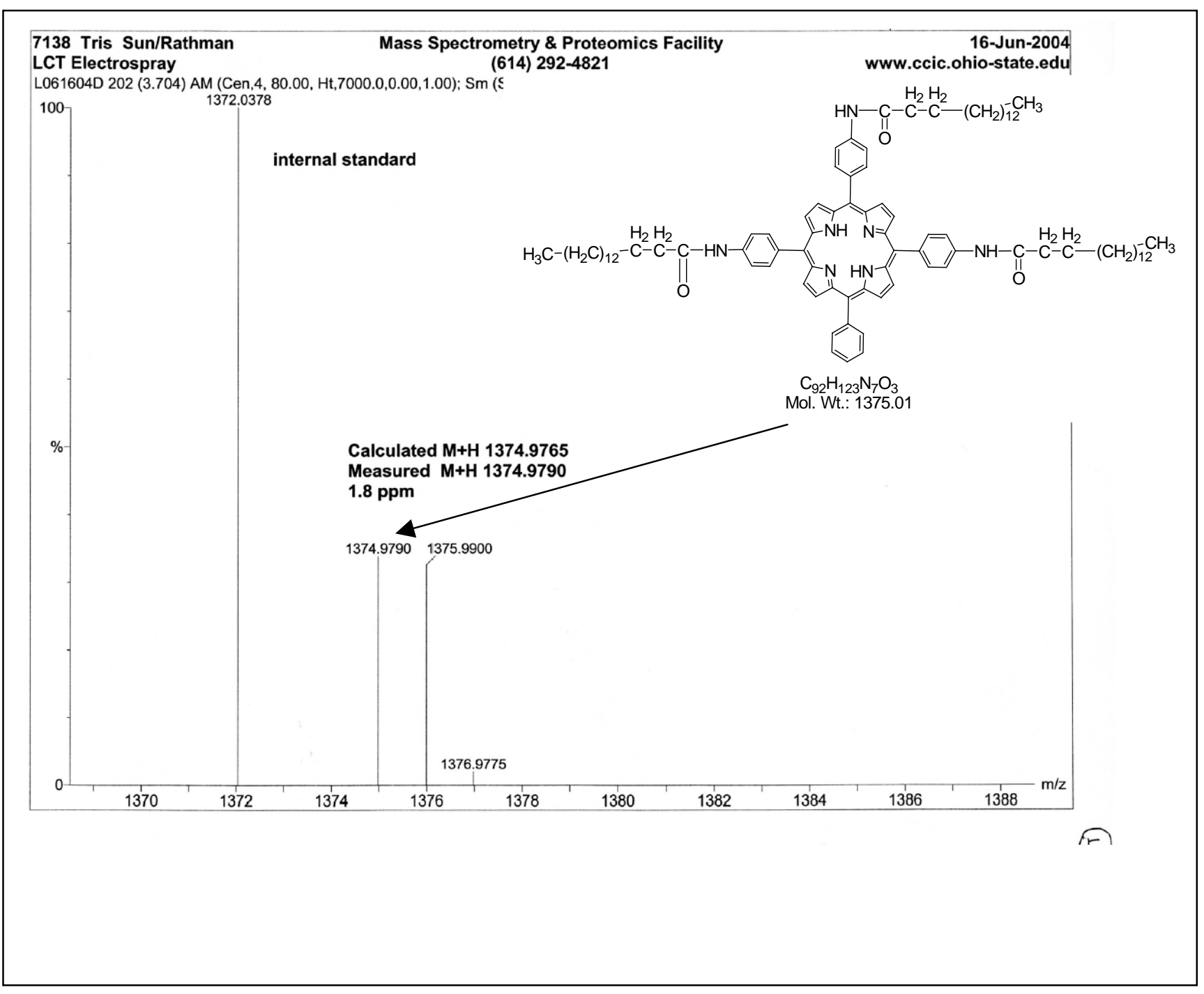




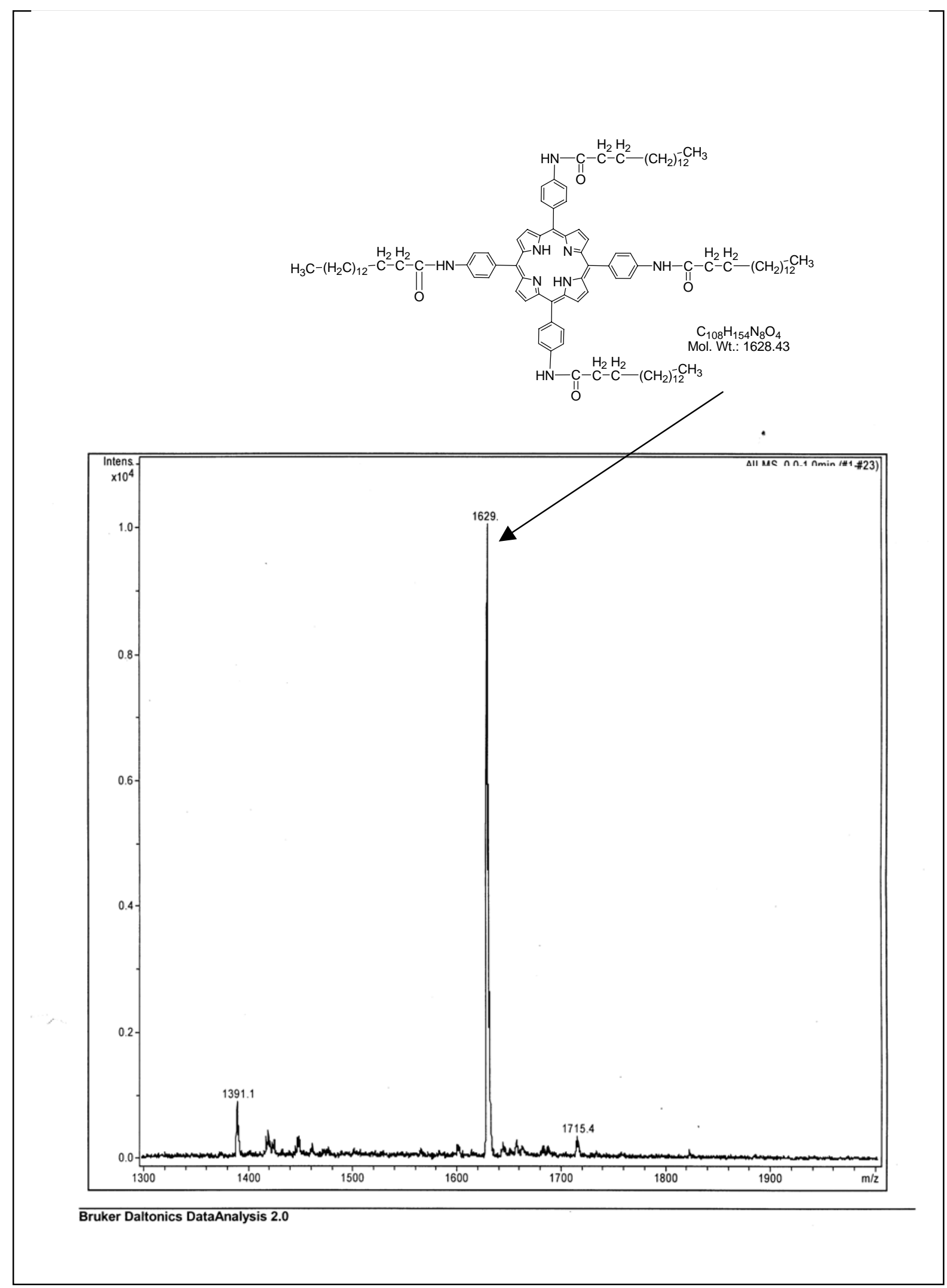

S8 


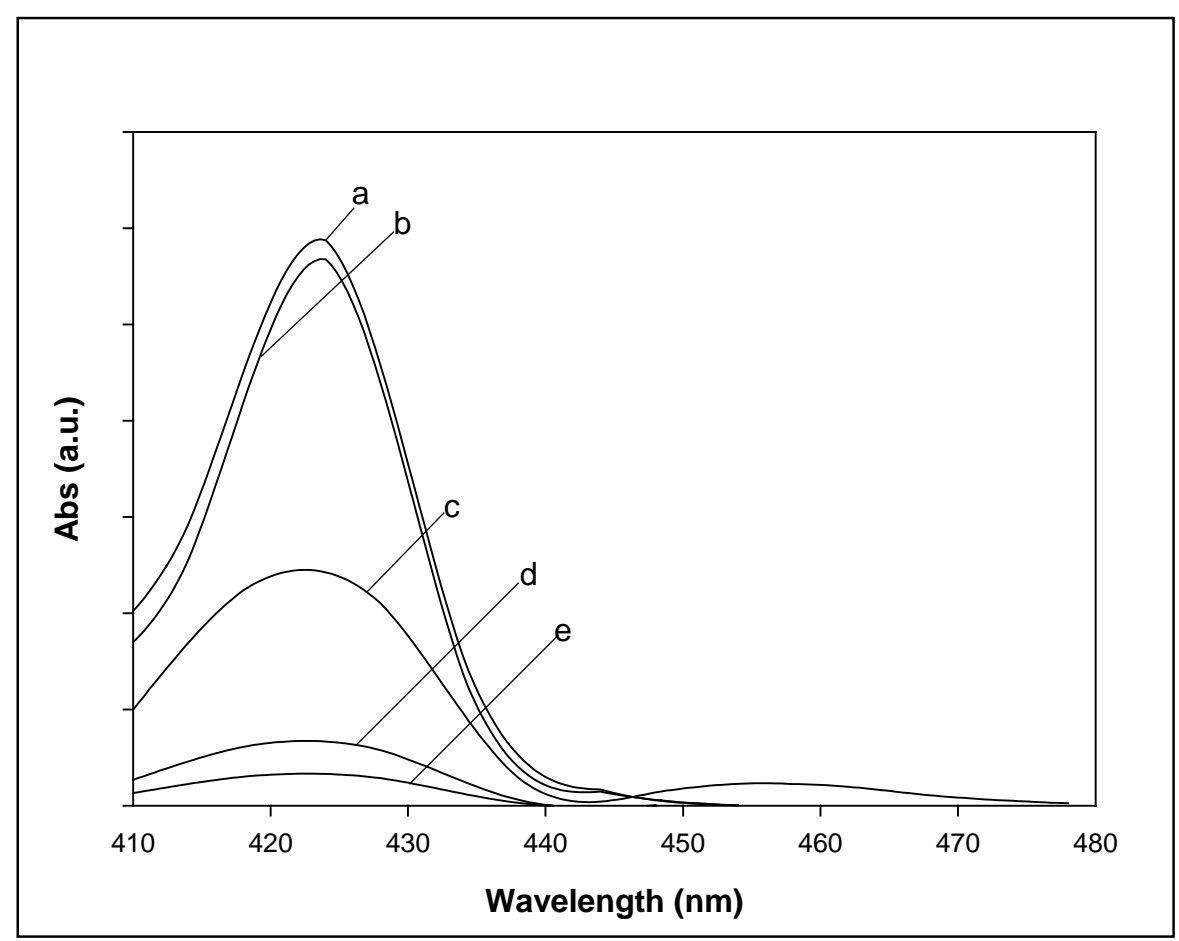

Electronic spectra for $\mathrm{L}_{4}$ in chloroform at various concentrations: (a) 2.7e-5 M, (b) 2.3e-5 M, (c) 1.5e-5 M, (d) 3.0e-6 M and (e) 1.5e-6 M. 